九州大学学術情報リポジトリ

Kyushu University Institutional Repository

\title{
Forecasting International Tourism Demand from Japan to Korea
}

Kim, Heung-Sik

Department of Social Development, Kyonggi Research Institute

Park, Koo-Won

Department of Social Development, Kyonggi Research Institute

Sakai, Masahiro

Laboratory of Forest Policy, Division of Forest Environment and Management Sciences,

Department of Forest and Forest Products Sciences, Faculty of Agriculture, Kyushu University

https://doi.org/10.5109/24471

出版情報: 九州大学大学院農学研究院紀要. 47 (1)，pp.179-193，2002-10-30. Kyushu University バージョン：

権利関係 : 


\title{
Forecasting International Tourism Demand from Japan to Korea
}

\author{
Heung-sik KIM*, Koo-won PARK* and Masahiro SAKAI \\ Laboratory of Forest Policy, Division of Forest Environment and Management Sciences, \\ Department of Forest and Forest Products Sciences, Faculty of Agriculture, \\ Kyushu University, Fukuoka 812-8581, Japan. \\ (Received June 21, 2002 and accepted June 25, 2002)
}

\begin{abstract}
An econometric model is very useful to understand relationships among economic variables such as tourism demand, income and travel cost. Long-term time series data are indispensable to implement an econometric model, which is consistent to the economic structure. Among econometric models of tourism demand, this study finds that a single equation multivariate time series model in the form of double-log linear model is the most relevant and practical model in estimating a parameter of Japanese tourists to Korea. As estimated income and price elastic ties of Japanese tourists are consistent with the economic theory, it can be used to the forecasting tourism demand.
\end{abstract}

\section{INTRODUCTION}

The international tourism sector is a rapidly growing sector of the global economy. According to the World Tourism Organization (WTO) data, the interest and significance of tourism has grown due to economic reasons as tourism demand been recognized as the largest industry in the world (WTO, 1999). The estimated overall global impact of tourism is US\$3.6 trillion and accounts for $8.2 \%$ of worldwide gross domestic product (GDP) in 2000 (Goeldner, Ritchie \& McIntosh, 1999, OECD, 1998). Its importance within the international trade in services has constantly increased. The share of international tourism in total international trade in services grew from $15 \%$ to approximately $24 \%$ between 1980 and $2000^{1)}$

In recent years the East Asia and Pacific (EAP) region has attracted an increased share of total international arrivals. The average growth rate over the last two decades has been $8.9 \%$ per annum. EAP region's total international arrivals expect to increase from 122 million persons in 2000 to 229 million persons in 2010 ie., an average growth rate of $7.7 \%$ per annum.

The growth prospects for international tourism in Korea are high in the $21 \mathrm{C}$. The international economic environment surrounding the Korean peninsula has rapidly changed. The rapprochement between South Korea and North Korea and the dramatic improvement in the economic performance of China have led to dramatic changes in the composition of visitor arrivals to the territory. Korea is not only located on the rim of the fast-growing East Asia and Pacific region with growth rates faster than other regions of

\footnotetext{
* Department of Social Development, Kyonggi Research Institute, 179-26, Pajang-dong, Changan-ku, Suwon, Kyong-gi Province, 440-290, Korea.

1) World Tourism Organization (WTO), Tourism Development Report: Policy and Trends, Madrid, Spain, 1989, and WTO, Current Travel and tourism Indicators, Madrid, Spain, 1996.
} 
Table 1. Regression Techniques to Estimate Tourism Demand

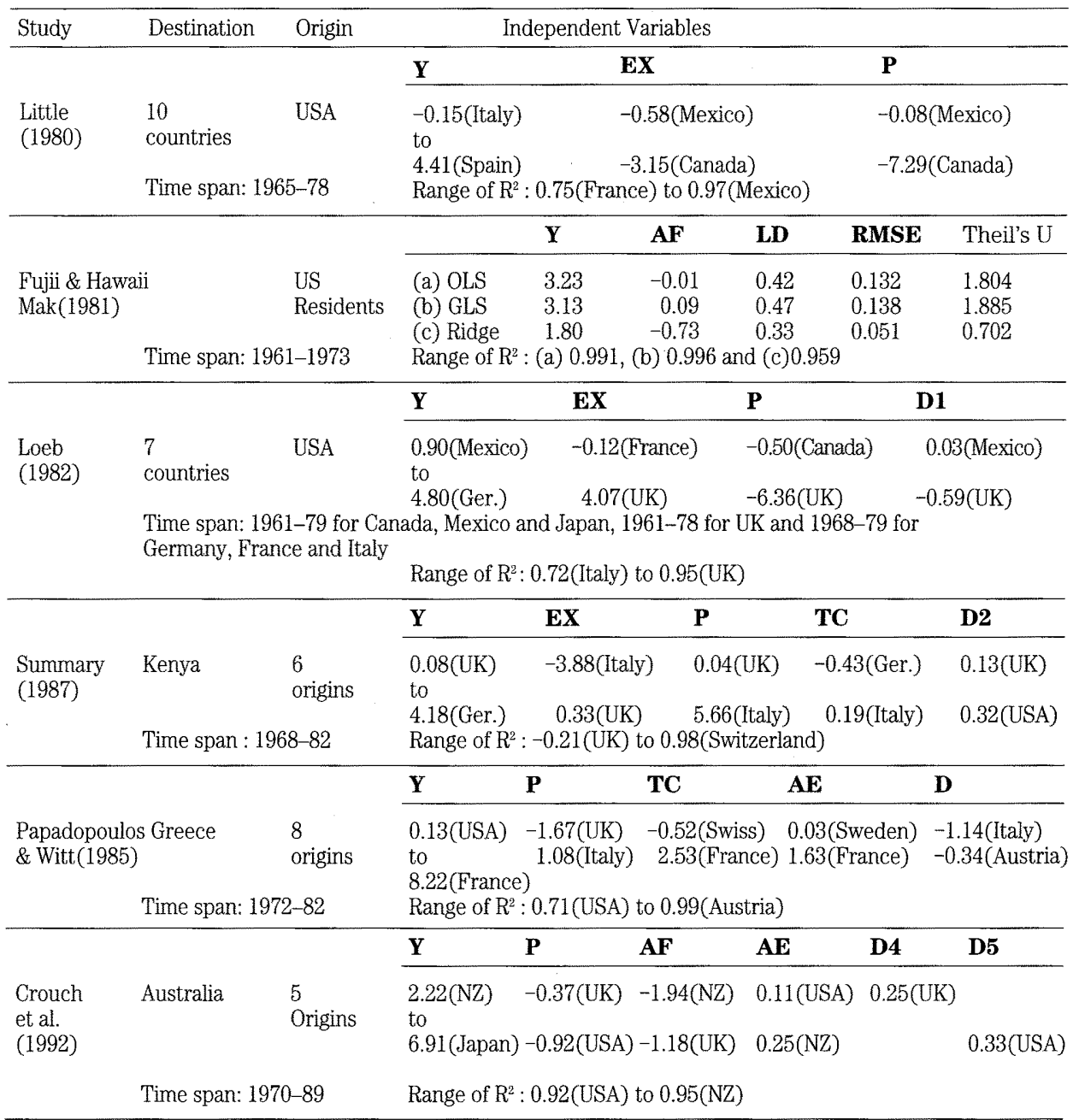

Notes: (1) $\mathrm{Y}=$ real per capita income, $\mathrm{EX}=$ exchange rate, $\mathrm{P}=$ relative price, $\mathrm{AF}=$ air fare, $\mathrm{LD}=$ one period lagged dependent variable, $\mathrm{TC}=$ real cost of travel, $\mathrm{AE}=$ advertising expenditure, D1 =the dummy variable for the Canadian Olympics $(1976=1$ otherwise $=0), \mathrm{D} 2=$ the dummy for the impact of the border closure with Tanzania (1968 to $1976=1$ otherwise $=0$ ), D3=the dummy variable representing the impact of a politically destabilising event (1974=1 otherwise=0), D4=world economic recession during 1982-1983 only for the UK (1982 to $1983=1$ otherwise=0) and D5=the 1988 EXPO and Bicentennial only for USA (1988=1 otherwise $=0)$ in Crouch et al.

(2) The dependent variable in the case of Little and Loeb was per capita expenditure, while in the rest of other studies it was the number of tourist arrivals per capita (Papadopoulos and Witt 1985) and the number of tourist arrivals (Summary 1987; Crouch et al. 1992).

(3) All studies used the log-linear form of the multiple regression model and estimated with OLS except for Loeb and Papadopoulos and Witt who estimated some models with the Cochrane--Orcutt procedure. 
the world, but also the international political and economic environment of the Korean peninsula has changed favorably for Korean inbound tourists

Furthermore, the WTO is likely to have a marked influence on the economic growth rates of most of the countries by virtue of its full implementation of the reduction of tariffs and non-tariff barriers. These recent unprecedented political and economic developments taking place in the North East Asian region, especially in the Korean peninsula, are expected to stimulate economic growth in this area, which in turn will influence the demand for the international tourism industry of Korea, as well as the demand for goods and services ${ }^{2}$.

The outline of this study is as follows. In section 2, we briefly review the existing works based on regression models and time series models to estimate demand functions for tourist arrivals or tourism expenditures. In section 3 , we discuss the definition of the variables used in the study and then develop alternative dynamic specifications for the estimation of tourist arrivals from Korea's major tourist-generating country, Japan. The preferred model is selected by comparing our alternative dynamic specification with the partial adjustment model on the basis of standard diagnostic tests and the non-nested hypothesis tests. Section 4 gives forecasts of international tourist arrivals from Japan over the forecasting period of 2001-2010. Concluding remarks are given in section 5 .

\section{LITERATURE SURVEY OF TOURISM DEMAND FORECASTS}

\section{Regression Models}

A number of tourism forecasting studies have used single equation regression models, time series models and a combination of techniques of regressions with the Delphi method or scenario writing. Detailed discussions of these methods can be found in Sheldon and Var (1985), Witt and Witt (1992) and Crouch (1994).

Regression models of forecasting relate the dependent variable to a number of explanatory variables. Such models are popular, because the consequences of the likely changes in the causal factors can be analysed. Examples of this forecasting method are Little (1980), Fujii and Mak (1981), Loeb (1982), Papadopoulos and Witt (1985), Summary (1987), and Crouch et al. (1992). The most common methodological problems of the existing regression models are as follows: (i) small sample size, thus very few degrees of freedom, (ii) very few diagnostic statistics, (iii) serial correlation (Little 1980; Papadopoulos and Witt 1985; Crouch et al. 1992) and (iv) multi-collinearity (Little 1980; Crouch et al. 1992). Virtually every study used the simple OLS method of estimation except for Fujii and Mak (1981), Loeb (1982) and Papadopoulos and Witt (1985) in which the Cochrane--Orcutt or the ridge regression methods have been used. All the studies have used log-linear functional form for the estimation of parameters. Annual time series data are commonly used. In addition, although income is found to be generally more significant than other explanatory variables, such as relative prices and exchange rate variables, estimated income elasticities varied considerably depending on the destination and the origin countries selected.

Table 1 summarizes some salient features of various econometric models of tourism

2) International Monetary Fund, World Economic Outlook, May 1994; pp. 83-84. 
demand in terms of tourism expenditure or tourist arrivals.

\section{Time Series Models}

An alternative technique for forecasting is time series analysis using the ARIMA method, also known as the Box-Jenkins method. Martin and Witt (1989) compared forecasts of international tourism demand obtained by standard econometric technique with forecasts based on six simple univariate time series models. Models were developed to forecast outward tourism from France, Germany, UK and USA. The data used in the study were annual, generally for the period 1965-1985, but had different time spans for various countries. Their preferred conventional regression models included the income of the origin country, the cost of living for tourists in the destination, the cost of living for tourists in substitute destinations and various types of dummy variables, differing slightly from country to country. Relative forecasting performance based on the conventional regression model are computed with 6 univariate time series models which are as follows: (i) naive no-change, (ii) naive proportional change, (iii) Brown's double exponential smoothing, (iv) trend fitting, (v) Gompertz and (vi) stepwise autoregressive models. In the tests of forecasting models, the no-change or "random walk" model was found to be the most accurate predictor of arrivals. The conventional econometric causal model was less accurate, but its ranking varied from country to country, ie., 2nd for USA, 3rd for France, 5th for UK and 7th for Germany for one--year-ahead forecasts.

Witt et al. (1992) forecasted visitor arrivals to Las Vegas using the exponential smoothing technique, which is designed to extrapolate historical data patterns into the future and then be noted that Witt et al. (1992) article is the only one reference that deals with forecasting domestic tourism demand. The relative forecasting performance of these models was evaluated with the mean absolute percentage error (MAPE).

The relative forecasting accuracy of the various techniques was examined by identifying the forecasting method with the lowest MAPE. In Austria, the MAPE of exponential smoothing model is lower than that of any other models. Autoregression model forecasts are relatively accurate, while ARIMA models are "second least accurate" forecasting techniques in terms of the MAPE (Witt et al. 1994; p.623). ARIMA forecasts for Spain and Greece had the lowest MAPE, followed by naive no change models and exponential smoothing model. Naive proportional change model forecasting is relatively the least accurate. In Italy, the overall MAPE of the Gompertz model is 16.9 which is smaller than 18.7 of the autoregression model and 27.3 of the ARIMA model. In contrast, naive 2 model had the largest MAPE, which means least accurate forecast. In summary, it can be said that ARIMA forecasts with the lower MAPE are relatively more accurate, followed by exponential smoothing and naive 1 models.

\section{Definition of the Variables}

As econometric models are behavioural models that attempt to measure 'cause and effect' relationships among variables, the causal explanatory variables, which will be employed in the analysis, are largely dependent on the variables being forecast ${ }^{3)}$.

The dependent variable of the demand for international tourism is, in general, measured in terms of (a) the number of tourist arrivals and departures or (b) tourist expenditures and receipts, or (c) the number of tourist nights and the average length of stay. 
Tourist expenditures and receipts measured in real money terms are preferable (Anastasopoulos 1984, p.97; O'Hagan and Harrison 1984, p.921) but reliable data are hard to obtain. A disadvantage with the average length of stay is that it does not allow for changes in average daily tourist expenditure. We shall therefore use the tourist arrivals as our dependent variable because data are available and reliable. A disadvantage of this choice is that the number of tourist arrivals is less responsive to the explanatory variables, because tourists can change microeconomic behaviour such as their length of stay and their daily expenditures level to adjust to changing circumstances. Although the population of tourist-generating countries is a determinant of the level of international tourism demand from a given origin, we do not include the population as a separate variable. In this study, the effect of population is accommodated by modifying the dependent variable as international tourism demand per capita (Barry and O'Hagan, 1972; Witt, 1980a; Witt and Martin, 1987).

On the other hand, explanatory variables influencing the international tourism demand must be selected by taking into account modelling constraints with regard to the degrees of freedom and reliability of data. Per capita real GNP for Japan is used in this study because it is hard to obtain personal disposable income figures for these countries. Per capita real GNP is calculated by deflating with the CPI of the corresponding country and then by dividing with the population of each country. Ideally, a ratio of the tourism price indices (TPIs) between the origin and destination countries should be used as the relative price variable. Such an index is not available. Therefore, the ratio of consumer price indices is used as a proxy for the relative prices. This is as follows: the tourism relative price is calculated as the CPI of Korea (destination) divided by the CPI of the origin country. In a similar manner, the relative exchange rate is calculated as the exchange rate of the origin country divided by the exchange rate of Korea (destination). This relative price and relative exchange indices are set equal to unity in 2000.

Transportation costs from the origin to the destination country tend to affect tourist arrivals. However, measuring the cost of transportation is considerably difficult due to various transport modes (viz., surface, sea and air), different fares according to seasonality and the class of travel (viz., car, train and plane). In addition, transportation costs are highly correlated with income. Therefore, many researchers excluded transportation from their models due to the reason discussed above. In this study, we don't include transportation costs as the reliable cost of travel before 1980 is not simply available, the possibility of the multicollinearity with the income variable and a number of modes and fares available to the destination.

Reliable data measuring the magnitude of destination-specific promotional activities by the Korean government are not available. Therefore, the present study ignores this variable. International tourist arrivals are influenced by other factors such as lifting of travel allowance restrictions, political disturbances and special events. Therefore, we shall use dummy variables to model these qualitative factors.

The data span for our study ranges from 1976 to 1999 and includes certain events such as the second energy crisis and political instability during 1979-1980 due to the

3) Pauline J. Sheldon and Turgut Var, "Tourism Forecasting: A Review of Empirical Research", Journal of Forecasting, Vol. 4, 1985; p185. 
assassination of President Park and the 1988 Seoul Olympic Games. Three dummy variables are considered for inclusion into the model as follows: (i) DUM1 =the second energy crisis and political instability in 1980, 1 for 1980 and 0 otherwise, (ii) DUM2=the Seoul Summer Olympics of 1988, 1 for 1988 and 0 otherwise.

\section{ESTIMATION OF TOURIST ARRIVALS}

\section{Unit Root Tests}

In the literature survey in section 2, a number of conventional econometric studies are based on the standard partial adjustment, specification to model the dynamics. Although this crude approach sometimes results in satisfactory results, it may be unsatisfactory because the actual dynamic adjustment process may be more complicated than the uniform speed of adjustment of the partial adjustment specification. Therefore, partial adjustment specification can induce functional form mis-specification and can give rise to the unnecessary inclusion or exclusion of explanatory variables and inaccurate estimates of the underlying elasticities.

Recent developments in time series analysis have shown that if the variables in a model are non-stationary, unit root tests should be conducted and the more sophisticated econometric techniques such as cointegration and error correction specifications or the less demanding general to specific technique should be used to estimate such specifications. It should be noted that at the time most of the previous studies were conducted, these developments did not have much influence. However, it is difficult to make a full use of these developments in our study because we do not have a large sample and unit root tests and cointegrating methods are essentially large sample methods ${ }^{4}$. Therefore, in what follows, we develop our alternative dynamic equations by using a diluted version of the general to specific approach of Hendry $(1979)^{\text {5) }}$.

Our approach is as follows. First, we estimate the standard partial adjustment specification. This is our baseline specification. Second, we estimate an alternative dynamic equation in which the current and one period lagged values of all the variables are used. In the general to specific approach suggested by Hendry (1979), it is necessary to include as many lagged values as are necessary to obtain residuals with the usual classical properties. However, since our sample size is small a large number of lagged values will decrease the degrees of freedom and the reliability of the estimates. Next we delete the insignificant variables, one at a time, by deleting the variable with the smallest $t$ ratio in

4) Since 1980 s the topic that has attracted the most interest in econometric circles is that of testing for unit roots. For a selective survey on this topic, see F. X. Diebold and M. Nerlove, Unit Roots in Economic Time Series: A Selective Survey," in T. Fomby and G. Rhodes (eds.), Advanced Econometrics, Vol. 8 (Greenwich, Conn.: JAI Press, 1990). For general to specific approach, see D. F Hendry," Predictive Failure and Econometric Modelling in Macroeconomics: The Transactions Demand for Money," in Paul Ormerod (eds.), Economic Modelling (London: Heinemann, 1979), ch. 9, pp. 217-242; and G. E Mizon, Model Selection Procedures," in M. J. Artis and A. R. Nobay (eds.), Studies in Current Economic Analysis (Oxford: Basil Blackwell, 1979), Ch. 4.

5) Our method is somewhat ad hoc and therefore the usual caveats should be kept in mind. Nevertheless our preferred spcifications turn out to be favoured to the partial adjustment equations on the basis of standard econometric practice for Japan and Taiwan but the standard partial adjustment specification is preferred to our alternative dynamic specification for the USA. 
the first instance. Each time a variable is deleted a variable deletion test is conducted to test if this is justified. In the final stage all the insignificant variables, found in this manner, are deleted and a joint variable deletion test is conducted to determine if the underlying null hypothesis that the coefficients of all the deleted variables are zero can be accepted at the $5 \%$ level of significance. If the null is rejected, wewill conduct the joint variable deletion test by adding variables with the largest $t$ ratios, one by one, until we obtain a parsimonious specification. This alternative equation and the baseline specification based on the partial adjustment are then subjected to the standard non-nested hypothesis tests to selectour final specification.

Before estimating our alternative dynamic specifications, we briefly discuss the time series properties of the variables involved in our model specifications. The results of applying both the Dickey-Fuller and the Augmented Dickey-Fuller (ADF) ${ }^{6}$ ) tests to the variables are reported in Table 2.

The null hypothesis is that the variable under investigation has a unit root, against the alternative that it does not. Table 2 reports tests of stationarity of the levels of the time-series about a non-zero mean with the trend and without the trend variables. The critical values of the test statistics are given in the brackets.

Specifically, for Y and EX in Table 2 for Japan, the null hypothesis of nonstationarity

Table 2. DICKEY-FULLER TESTS ${ }^{1.2}$ JAPAN (1976-1999)

\begin{tabular}{|c|c|c|c|c|}
\hline & $\frac{\mathrm{DF}}{\text { without trend }}$ & with trend & $\frac{\operatorname{ADF}(1)}{\text { without trend }}$ & with trend \\
\hline $\mathbf{T A}$ & $-0.018(-3.052)$ & $-1.319(-3.712)$ & $-0.453(-3.066)$ & $-2.206(-3.735)$ \\
\hline $\mathbf{Y}$ & $-0.500(-3.052)$ & $-1.759(-3.712)$ & $-0.392(-3.066)$ & $-2.204(-3.735)$ \\
\hline PE & $-2.131(-3.052)$ & $-1.351(-3.712)$ & $-3.251(-3.066)^{*}$ & $-6.061(-3.735)^{*}$ \\
\hline $\mathbf{E X}$ & $-1.077(-3.052)$ & $-2.317(-3.712)$ & $-1.089(-3.066)$ & $-2.754(-3.735)$ \\
\hline$\triangle \mathbf{T A}$ & $-2.458(-3.066)$ & $-2.526(-3.735)$ & $-2.163(-3.082)$ & $-2.499(-3.761)$ \\
\hline$\triangle \mathbf{T}$ & $-3.245(-3.066)^{*}$ & $-3.122(-3.735)$ & $-2.788(-3.082)$ & $-2.774(-3.761)$ \\
\hline$\triangle \mathbf{P}$ & $-1.641(-3.066)$ & $-2.196(-3.735)$ & $-2.544(-3.082)$ & $-2.630(-3.761)$ \\
\hline$\triangle \mathbf{E X}$ & $-3.670(-3.066)^{*}$ & $-3.579(-3.735)$ & $-3.015(-3.082)$ & $-2.746(-3.761)$ \\
\hline$\triangle \mathbf{2 T A}$ & $-4.499(-3.082)^{*}$ & $-4.315(-3.761)^{*}$ & $-3.467(-3.100) *$ & $-3.327(-3.792)$ \\
\hline$\triangle \mathbf{2 Y}$ & $-5.815(-3.082)^{*}$ & $-5.751(-3.761)^{*}$ & $-3.451(-3.100)^{*}$ & $-3.271(-3.792)$ \\
\hline$\triangle \mathbf{2 P}$ & $-2.973(-3.082)$ & $-2.767(-3.761)$ & $-2.468(-3.100)$ & $-2.401(-3.792)$ \\
\hline$\triangle \mathbf{2 E X}$ & $-5.840(-3.082)^{*}$ & $-5.756(-3.761) *$ & $-3.739(-3.100)^{*}$ & $-3.552(-3.792)$ \\
\hline
\end{tabular}

Notes : $1.95 \%$ critical values in brackets when available and $*$ denotes that the null of nonstationarity can be rejected at the $5 \%$ level. All variables are expressed in logarithuns

2. $\mathrm{TA}=$ Tourist Arrivals, $\mathrm{Y}=$ per capita $\mathrm{GNP}, \mathrm{P}=$ relative prices, $\mathrm{EX}=$ relative exchange rate

3. $\triangle$ =first difference, $\triangle 2=$ second difference

6) Ideally in the ADF test as many lagged first differences of the variable as are nccessary to obtain white noise residuals should be used. However, since our sample size is small we have only used one lagged first difference of the variable. 
cannot be rejected at the $5 \%$ level. For $\mathrm{P}$, the null hypothesis is rejected at the $5 \%$ level only in the case of ADF test. Relative price variable was found to be I (0). For $\triangle \mathrm{EX}$, the null hypothesis is rejected at the $5 \%$ level only in the case of DF test without the trend variable. Relative exchange rate variable is integrated to order one, ie., I (1). We test if $\triangle^{2} Y$ is stationary and found that $Y$ is integrated to order two, ie., I (2). It should be noted that for TA and TA the null hypothesis that they are $I$ (1) is rejected. Therefore, we tested if $\triangle^{2} \mathrm{TA}$ is stationary and found that TA is I (2).

It is important to note that we do not mean that there is no scope for the utilization of the cointegration techniques in this area. Our inconclusive results are partly due to the small size of our sample. Larger samples might yield far superior and more conclusive

Table 3. A Selection of Estimated Regression Models of Tourist Arrivals from Japan to Korea (1976-1999)

\begin{tabular}{|c|c|c|c|c|c|c|}
\hline & Eq.1 & Eq.2 & Eq.3 & Eq.4 & Eq.5 & Eq.6 \\
\hline Regressor & & & & coefficients & & \\
\hline Constant & $\begin{array}{c}-2.243 \\
(-0.833)\end{array}$ & $\begin{array}{c}-2.408 \\
(-3.600)\end{array}$ & $\begin{array}{c}-5.140 \\
(-1.437)\end{array}$ & $\begin{array}{c}-5.793 \\
(-2.945)\end{array}$ & $\begin{array}{c}-8.895 \\
(-10.994)\end{array}$ & $\begin{array}{c}-2.298 \\
(-3.036)\end{array}$ \\
\hline $\log Y$ & $\begin{array}{c}0.454 \\
(1.029)\end{array}$ & $\begin{array}{c}0.485 \\
(4.114)\end{array}$ & $\begin{array}{c}1.337 \\
(1.912)\end{array}$ & $\begin{array}{c}1.085 \\
(3.288)\end{array}$ & $\begin{array}{c}1.547 \\
(11.897)\end{array}$ & $\begin{array}{c}0.427 \\
(3.319)\end{array}$ \\
\hline $\log P$ & $\begin{array}{c}-0.318 \\
(-1.883)\end{array}$ & $\begin{array}{c}-0.342 \\
(-3.037)\end{array}$ & $\begin{array}{c}-0.993 \\
(-1.359)\end{array}$ & $\begin{array}{c}-1.309 \\
(-3.430)\end{array}$ & $\begin{array}{c}-0.166 \\
(-0.857)\end{array}$ & \\
\hline $\log \mathrm{EX}$ & $\begin{array}{c}-0.006 \\
(-0.017)\end{array}$ & & $\begin{array}{c}-0.827 \\
(-1.301)\end{array}$ & $\begin{array}{c}-0.545 \\
(-1.887)\end{array}$ & $\begin{array}{c}-0.775 \\
(-3.827)\end{array}$ & \\
\hline $\log \mathrm{TA}(-1)$ & $\begin{array}{c}0.647 \\
(2.547)\end{array}$ & $\begin{array}{c}0.624 \\
(6.282)\end{array}$ & $\begin{array}{l}0.438 \\
(1.301)\end{array}$ & $\begin{array}{c}0.344 \\
(1.944)\end{array}$ & & $\begin{array}{c}0.645 \\
(5.782)\end{array}$ \\
\hline $\log Y(-1)$ & & & $\begin{array}{c}-0.421 \\
(-0.564)\end{array}$ & & & \\
\hline $\log P(-1)$ & & & $\begin{array}{c}0.954 \\
(1.625)\end{array}$ & $\begin{array}{c}1.090 \\
(2.763)\end{array}$ & & $\begin{array}{c}-0.252 \\
(-2.227)\end{array}$ \\
\hline $\log \mathrm{EX}(-1)$ & & & $\begin{array}{c}0.281 \\
(0.527)\end{array}$ & & & \\
\hline D1 & $\begin{array}{c}-0.295 \\
(-3.760)\end{array}$ & $\begin{array}{c}-0.290 \\
(-4.397)\end{array}$ & $\begin{array}{c}-0.096 \\
(-0.837)\end{array}$ & $\begin{array}{c}-0.124 \\
(-1.523)\end{array}$ & $\begin{array}{c}-0.198 \\
(-2.358)\end{array}$ & $\begin{array}{c}-0.326 \\
(-4.452)\end{array}$ \\
\hline $\mathrm{D} 2$ & $\begin{array}{c}0.036 \\
(0.406)\end{array}$ & & $\begin{array}{c}-0.019 \\
(-0.219)\end{array}$ & & $\begin{array}{c}-0.101 \\
(-1.163)\end{array}$ & \\
\hline adjusted $\mathbf{R}^{2}$ & 0.975 & 0.979 & 0.980 & 0.986 & 0.960 & 0.973 \\
\hline D.W. & 1.473 & 1.416 & 1.691 & 1.481 & 1.426 & 1.372 \\
\hline$\chi^{2}(1)$ & 1.568 & 1.554 & 0.941 & 1.385 & 2.122 & 1.662 \\
\hline$x^{2}$ (ff) & 1.151 & 1.102 & 1.049 & 1.406 & 3.012 & 1.993 \\
\hline$\chi^{2}(\mathbf{n})$ & 0.532 & 0.426 & 0.699 & 0.854 & 0.202 & 0.438 \\
\hline$\chi^{2}$ (hs) & 1.634 & 2.142 & 0.449 & 1.698 & 0.929 & 0.671 \\
\hline S.E.E & 0.064 & 0.060 & 0.057 & 0.049 & 0.081 & 0.067 \\
\hline
\end{tabular}

Notes : 1. figures in brackets are t-ratio.

2. $\chi^{2}(1)=$ Lagrange multiplier test for first order residual serial correlation.

$\chi^{2}$ (ff)=Ramsey's RESET test for functional form mis-specification.

$\chi^{2}(\mathrm{n})=$ Based on a test of skewness and kurtosis of residuals for normality of errors.

$\chi^{2}$ (hs) $=$ Based on the regression of squared residuals on squared fitted values for heteroscedasticity.

3. Microfit by Pesaran and Pesaran (1991) has been used. 
results when these techniques are used.

\section{Estimation of Japanese Tourist Arrivals}

We start with the standard partial adjustment specification regarding the tourist arrivals from Japan to Korea. Table 3 illustrates various equations. All the variables, except the dummies, are transformed into their logarithms and the respective coefficients are the estimates of elasticities.

In equation 1, the coefficients of all the explanatory variables, except that of relative exchange rate variable $\mathrm{EX}$, have the expected signs. One period lagged dependent variable and dummy variable D1 are significant at the $5 \%$ level but the relative price is significant at the $10 \%$ level. All the $\chi^{2}$ diagnostic test statistics for the first-order serial correlation, functional form mis-specification, normality and heteroscedasticity in the residuals are all insignificant at the $5 \%$ level.

We conducted a variable deletion test by constraining the coefficients of the three insignificant variables, viz., $\ln Y_{t}, \ln \mathrm{EX}_{2}$ and $\mathrm{D} 2$ to be zero one at a time, starting with $\ln \mathrm{Ex}_{\mathrm{t}}$ which has the smallest $t$ ratio but to conserve space we shall not report the details of this regression and test results. We imposed the restriction that the coefficients of the two insignificant variables, $\ln \mathrm{EX}_{1}$ and $\mathrm{D} 2$, are jointly zero and the estimates are given by equation 2.

The variable deletion test statistic is insignificant at the $5 \%$ level. Its computed value is 0.362 and its critical value is 5.99 at the $5 \%$ level. In equation 2 , the coefficients of all the explanatory variables have expected signs and all are significant. The $\chi^{2}$ diagnostic test statistics are insignificant at the $5 \%$ level.

Equations 3 to 6 in Table 3 explain our alternative dynamic specifications. Equation 3 includes all the current and one period lagged explanatory variables as well as the one period lagged dependent variable. Estimated coefficients of all the lagged explanatory variables are insignificant. The coefficient of the income $(\mathrm{Y})$ is significant, at the $10 \%$ level and has the expected sign but the coefficient of relative prices (P) and relative exchange rate $(\mathrm{EX})$ are insignificant at the $10 \%$ level and have the wrong sign. The $\chi^{2}$ diagnostic test statistics of equation 3 are very similar to those in equation 1 except that the first-order serial correlation and the heteroscedasticity statistics are less.

We conducted a variable deletion test by constraining the coefficients of the eight insignificant variables viz. $\ln \mathrm{P}_{\mathrm{t}}, \ln \mathrm{EX}_{\mathrm{t}}, \ln \mathrm{TA} \mathrm{A}_{\mathrm{t}-1}, \ln \mathrm{Y}_{\mathrm{t}-1}, \ln \mathrm{P}_{\mathrm{t}-1}$ and $\operatorname{lnEX_{\mathrm {t}-1}}, \mathrm{D} 1$ and D2 to be zero one by one at a time, starting with $\mathrm{D} 2$ which has the smallest $t$ ratio. We conducted similar variable deletion tests for each insignificant variable and found that in none of these equations could the null hypothesis be rejected at the 5\% level. To conserve space we shall not report the details of these regressions and test results.

Then we imposed the restriction that the coefficients of all the insignificant variables are jointly zero and the estimates are given by equation 4 . The variable deletion test statistic is significant at the $5 \%$ level, implying that this restriction can reject the null hypothesis that these variables can be deleted from the regression. Its computed value of 11.42 exceeded the critical value of 9.49 at the $5 \%$ level.

Since the null is rejected, we will conduct the joint variable deletion test by adding variables with the largest $t$ ratios, one by one, until we obtain a parsimonious specification. To conserve space we shall not report the details of these regressions and test 
results. We imposed the restriction that the coefficients of the three insignificant variables, $\ln Y_{t-1}, \operatorname{lnEX_{t-1}}$ and D2, are jointly zero and the estimates are given by equation 5 . The variable deletion test statistic could not reject this restriction. The $\chi^{2}$ diagnostic test statistic was 0.741 and its critical value was 7.81 .

Finally, we conduct therefore a joint variable deletion test by constraining the coefficients of all the insignificant variables, except for one period lagged relative price $\left(\ln \mathrm{P}_{11}\right)$ with the largest $t$ ratio and for one period lagged dependent variable with the second largest $t$ ratio, to be zero and the estimates are given by equation 6 . The variable deletion test could not reject this restriction. The $\chi^{2}$ test statistic was 9.67 and its critical value was 11.1 at the $5 \%$ level. Therefore this is our preferred alternative specification. In equation 6 , it is found that the $\chi^{2}$ diagnostic tests statistics for the first-order serial correlation, functional form mis-specification, normality and heteroscedasticity in the residuals are all insignificant.

We shall compare now equation 2 based on the standard partial adjustment specification with equation 6 based on the alternative dynamic specification. Summary statistics of both equations are very similar. The $\mathrm{S}$. E. of equation 2 of 0.060 is marginally smaller than 0.067 of equation 6 . In addition, equation 2 is better than equation 6 in terms of the functional form mis-specification test.

We shall now subject our alternative specification and the partial adjustment equation to the non-nested hypothesis tests because the dynamics underlying these 2 equations are not nested. There are several non-nested tests that are available in the economic literature. However, the tests to be reported here are the NT test, W test, J test and JA test? .

These tests examine whether one of the two models being compared dominates the other. Thus model 1 is said to dominate model 2 if the explanatory variables under model 2 fail to explain the behaviour of the specification under model 1, and vice versa. Table 4 reports the values of the test statistics for the alternative tests for the partial adjustment model (equation 2) and the alternative dynamic model (equation 6). When the partial adjustment model (equation 2) is assumed to be the null, all the test statistics are insignificant at the $5 \%$ level, implying that the alternative dynamic model (equation 6 ) can be rejected against the partial adjustment specification (eq.2). Since these tests reject the alternative dynamic specification (eq.6), we may accept the null that the specification in equation 2 is superior.

When reversed, ie., the alternative dynamic specification (eq.6) is assumed to be the null, all the test statistics are significant. They suggest that the alternative dynamic specification (eq.6) can be rejected against the partial adjustment specification (eq.2) at the $5 \%$ level. In summary, the results of the non-nested tests favour eq. 2 based on the standard partial adjustment approach for Japan.

Results of model selection criteria based on the AIC and SBIC are also reported in Table 4. Since AIC (eq.2: eq.6) and SBIC (eq.2: eq.6) are positive, equation 2 is preferred to equation 6 . The results of the model selection criteria are consistent with those of

7) For further detailed discussions on non-nested tests see Godfrey and Pesaran (1983) and McAleer (1987). Note that the four non-nested hypothesis test statistics, reported in Table 8.4, are asymptotically distributed as $\mathrm{N}(0,1)$. 
Table 4. Non-nested Hypothesis Tests (Japan), 1976-1999

\begin{tabular}{lcc}
\hline Test & Eq.2 : Eq.6 & Eq.6 : Eq.2 \\
\hline NT-test & 1.384 & -2.447 \\
W-test & 1.515 & -2.168 \\
J-test & -1.838 & 2.645 \\
JA-test & -1.838 & 2.645 \\
& & \\
AIC of eq.2 versus eq. $6=1.908$ & & \\
SBIC of eq.2 versus eq. $6=1.908$ & & \\
\hline
\end{tabular}

Note: Equation 6: Equation 2 means the null is equation 6 and the alternative is equation 2. Similarly, Eq.2: Eq.6 means that our alternative specification in equation 6 is tested against the standard partial adjustment specification in equation 2 .

non-nested tests.

In equation 2 , the coefficients of the explanatory variables are significant and have expected signs. From the results in equation 2 , it is seen that the income elasticity is 0.485 , implying that for a one percent increase in the real income, the demand for international tourism of the Japanese tourists to Korea increases by about 0.49 percent. It should be noted that the estimated short-run relative price elasticity is about -0.342 and the long-run elasticity is -0.910 respectively. The discrepancy between the short-run and the long-run elasticities can be attributed to the inertia, or slow diffusion of information, or certain rigidities in contracts over tours. Hence, tourism demand is unlikely to drop by a large amount in the short-run due to the price changes as the long-run elasticity would imply. In the long-run, the increase or decrease in price will have a greater effect on tourist arrivals because the inertia factor, as discussed previously, would have been accounted for. The coefficient of the dummy variable D1 for political instability in Korea in 1980 is -0.29 . It has the expected sign and is significant.

\section{FORECASTS TO THE YEAR 2010}

The East Asia and Pacific regions, including Korea, are expected to continue their outstanding growth performance throughout the $21 \mathrm{C}$ just like the $1990 \mathrm{~s}$. The quality of forecasts is largely dependent on the premises of forecasts: (i) the economic structure of independent variables used for the forecasts and the quantitative relationship between independent variables and dependent variable are constant for the forecasting period of 2001-2010. It means that the estimated coefficients of the tourism demand function are applied over the forecasting period, (ii) it is assumed that the phenomenon of tourism market saturation from major tourist-generating countries does not appear throughout the forecasting period, (iii) there is no constraint in the supply side. That is, forecasts from the model are demand forecasts, which estimate the number of visitor arrivals to Korea that would come if the supply factors such as airport capacity and accommodation are not a problem ${ }^{8)}$, and (iv) other factors otherwise stated are assumed to be constant throughout the forecasting period. Also, despite food shortages, the unavailability of daily necessities and serious economic recession in North Korea, it is assumed that the unexpected collapse of North Korea will not take place. 
Table 5. Average Annual Growth Rate of Explanatory Variables in Regression Models of Tourist Arrivals from Japan to Korea, 2001-2010

\begin{tabular}{lccccc}
\hline & $1976-1981$ & $1981-1985$ & $1986-1990$ & $1990-1999$ & $2001-2010$ \\
\hline CPI & 18.5 & 3.8 & 6.1 & 6.8 & 3.3 \\
Korea & 5.8 & 2.2 & 1.5 & 2.1 & 0.6 \\
Japan & & & & & \\
& & & & 4.3 & -1.6 \\
Exchange rate & 7.1 & 6.3 & -5.3 & -8.4 & -0.8 \\
Korea & -5.8 & 2.0 & -3.7 & & \\
Japan & & & & 2.8 & 3.5 \\
Real GDP & 5.2 & 4.0 & 5.1 & & \\
Japan & & & & 0.3 & 0.3 \\
Population & 0.9 & 0.7 & 0.4 & & \\
Japan & & & &
\end{tabular}

Sources: IMF, World Economic Outlook, 2000.

__, 1999 International Financial Statistics Yearbook, 2000. International Financial Statistics, various issues.

OECD, OECD Economic Outlook, 2000.

$\mathrm{ADB}, 1999$ Asian Economic Outlook, 2000.

European Commission, Energy in Europe 1999 Annual Energy Review, 2000.

Table 5 indicates the likely magnitude of these changes. These values should be regarded as the minimum increases likely to occur. CPI of all the countries for the forecasting period is expected to increase but its growth rate is expected to be lower than that for the period 1994-1999. An average growth rate of 3.3\% is expected for Korea.

CPI for Japan is expected to be lower than that of the period 1994-1999, averaging $0.6 \%$ annually for the forecasting period.

The currencies of Japan and Korea are expected to appreciate against the US dollar. Japanese yen is expected to appreciate at $0.8 \%$ and Korean currency is also expected to appreciate at $1.6 \%$ for the forecasting period.

The average annual growth rate of real GDP in Japan is expected to accelerate over the same period. Despite the slow recovery from recession during the 1990s, Japan is expected to grow at $3.5 \%$ for the period 2001-2010.

The value and an average annual growth rate of independent variables in the model over the forecasting period of 2001-2010 are calculated on the basis of the IMF medium-term scenarios for Japan ${ }^{9}$. The regression equations forecast tourist arrivals from Japan to Korea by using the values of independent variables in the model over the forecasting period of 2001-2010.

Table 6 gives forecasts of foreign tourist arrivals by Japan over the forecasting period

8) Michael Poole, Forecasting Methodology, BTR occasional paper No. 3, Bureau of Tourism Research, 1988 , p. 5. 
of 2001-2010. Although tourist arrivals from Japan had grown at 5.7\% annually during $1991-2000$, the average annual growth rate of $5.0 \%$ for the forecasting period is expected to be lower. The forecasts for Japanese tourist arrivals to Korea will increase from $2,595,656$ in 2001 to $4,026,714$ in 2010 .

Table 6. Forecasts of International Tourist Arrivals from Japan to Korea, $2001-2010$

\begin{tabular}{ccc}
\hline & Japanese Tourist Arrivals & Total Tourist Arrivals \\
\hline 2001 & $2,595,656$ & $5,582,056$ \\
2002 & $2,725,439$ & $5,861,159$ \\
2003 & $2,861,711$ & $6,154,217$ \\
2004 & $3,004,796$ & $6,461,927$ \\
2005 & $3,155,036$ & $6,785,024$ \\
2006 & $3,312,788$ & $7,124,275$ \\
2007 & $3,478,427$ & $7,480,488$ \\
2008 & $3,652,349$ & $7,854,514$ \\
2009 & $3,834,966$ & $8,247,239$ \\
2010 & $4,026,714$ & $8,659,600$ \\
\hline
\end{tabular}

If it is assumed that a share of Japan to total tourist arrivals in 2000 (46.5\%) maintains, total tourist arrivals to Korea is expected to rise $8,659,600$ up to the year 2010 .

\section{CONCLUDING REMARKS}

Some conclusions can be drawn from our literature survey on tourism demand forecasting. A number of studies are based on the small samples with an average period of about 14 years, and most of the studies have used time-series annual data. None of these earlier multiple regression studies reported a comprehensive set of $\chi^{2}$ diagnostic tests. Overall, univariate time series and the ARIMA models are found to be superior to conventional econometric causal models in terms of the forecasting accuracy based on the mean absolute percentage error but most time series studies did not conduct unit root tests to check whether variables involved in the equations are non-stationary. Therefore, we need to be careful about interpreting the ARIMA forecasting results.

From our regression results of Japan, the estimated coefficients of most of the explanatory variables have expected signs and are statistically significant, which are in accordance with a priori economic expectations. The coefficient of income for Japan is significant and has the expected sign. Estimated income elasticity of 0.485 implies that for a one percent increase in the real income, the demand for international tourism of the Japanese tourists to Korea increases by about $0.49 \%$. Changes in relative price in the long-run have a greater effect on tourist arrivals from Japan than in the short-run. It

9) For more details, see Paul Masson, Steven Symansky, and Guy Meredith, "MULTIMOD Mark II: A Revised and Extended Model," IMF Occasional Paper 71 (July 1990), Leonardo Bartolini, Assaf Razin, and Steven Symansky, Fiscal Restructuring in the G-7," (IMF Working paper, forthcoming), and IMF, World Economic Outlook, October 1994, Annex II, p. 104. 
should be noted that the estimated short-run relative price elasticity is about -0.342 and the long-run elasticity is -0.910 respectively. The discrepancy between the short-run and the long-run elasticities can be attributed to the inertia, or slow diffusion of information, or certain rigidities in contracts over tours. Hence, tourism demand is unlikely to drop by a large amount in the short-run due to the price changes as the long-run elasticity would imply. In the long-run, the increase or decrease in price will have a greater effect on tourist arrivals because the inertia factor, as discussed previously, would have been accounted for. The coefficient of the dummy variable D1 for political instability in Korea in 1980 is -0.29 . It has the expected sign and is significant.

The Korean government set the target of 10 million tourist arrivals up to the year 2010. In terms of tourist arrivals, this aim can be achieved only when tourist arrivals grow at $8.8 \%$ annually for the period 2001-2010. However, the results of our forecasts seem to indicate that perhaps this target is unrealistic when the share (46.5\%) of Japan in 2000 is assumed to be maintained up to the year 2010 and total visitor arrivals from Japan are expected to grow at $5.0 \%$ per annum.

The growth prospects of the international tourism industry in Korea are expected to be very bright in the $21 \mathrm{c}$ but competition for the growing share of the world tourism industry is expected to intensify in the future. Therefore, tourism policy should be formulated and implemented to keep up with key trends in world tourism and to enforce the international competitiveness of the Korean tourism industry for further development. Increased resources to upgrade and to maintain tourism infrastructure in Korea will be required along with strong administrative assistance to the industry. Tourism products should be also developed to keep up with distinct characteristics of each potential target market of Korea as well as market diversification efforts to enhance the growth rate of international tourist arrivals to Korea. Furthermore, it is imperative that for accurate forecasting the Korean government play its role in collecting more disaggregated, accurate and timely research data with regard to travel market segments such as holiday activity participation, geographical and socio-demographic features and the purpose of trip. Finally, the model developed in this study has many limitations, some of which are sometimes inevitable due to the lack of reliable data.

\section{REFERENCES}

Crouch, G. I. 1994 "The Study of International Tourism Demand: A Survey of Practice," Journal of Travel Research, 32(4): 41-57.

Crouch, G. I., L. Schultz, and P. Valerio 1992 "Marketing International Tourism to Australia: A Regression Analysis," Tourism Management, 13(2): 196-208.

Edwards, A. 1988 "International Tourism Forecasts to 1999," The Economic Intelligence Unit, Special Report No, 1142, London: England.

Fritz, R. G., C. Brandon, and J. Xander 1984 "Combining Time-Series and Econometric Forecasts of Tourism Activity," Annals of Tourism Research, 11(2): 219-29.

Fujii, E. T., and J. Mak 1981 "Forecasting Tourism Demand: Some Methodological Issues," Annals of Regional Science, 15(2): 72-82.

Hylleberg, S. and G. E. Mizon 1989 "A Note on the Distribution of the Least Squares Estimator of a Random Walk with Drift," Economic Letters, 29: 225-230.

International Monetary Fund 2000 World Economic Outlook, IMF.

Martin, C. A., and S. F. Witt 1987 "Tourism Demand Forecasting Models: Choice of Appropriate Variable to Represent Tourists' Cost of Living," Tourism Management, 8(3): 223-45. 
Masson, P., S. Symansky, and G. Meredith 1990 "MULTIMOD Mark II: A Revised and Extended Model," IMF Occasional Paper 71

McAleer, M. 1987 "Specification tests for separate models: A Survey," M. King and E. A. Giles (eds), in Specification Analysis in the Linear Model, Routledge and Kegan Paul, London: 146-196.

Morley, C. 1991 "Forecasting Tourism Demand Using Extrapolative Time Series Methods," Journal of Tourism Studies, 4(1): 19-25.

Pesaran, M. H. and B. Pesaran 1991 MICROFIT 3.0: An Interactive Econometric Software Package (User Manual), Oxford University Press.

Poole, M. 1988 Forecasting Methodology, Occasional Paper No. 3, Australia: Bureau of Tourism Research.

Rao, B. B. 1992 "Some Further Evidence on the Policy Ineffectiveness Proposition," Economic Joumal, 102(September): 1244-1250.

Rao, B. B. 1993 "Unit root hypothesis, new classical and Keynesian models," Economics Letters, 41: $47-52$.

Sheldon, P. J. 1993 "Forecasting Tourism: Expenditures versus Arrivals," Joumal of Travel Research, 32(1): $13-20$.

Smeral, E., S. F. Witt, and C. A. Witt 1992 "Econometric Forecasts: Tourism Trends to 2000," Annals of Tourism Research, 19: 451-52.

Summary, R. 1987 "Estimation of Tourism Demand by Multivariable Regression Analysis: Evidence from Kenya," Tourism Management, 8(4): 317-22.

Uysal, M. and J. L. Crompton 1984 "Determinants of Demand for International Tourist Flows to Turkey," Tourism Management, $5(4): 288-97$.

Witt, S. F., G. D. Newbold, and A. J. Watkins 1992 "Forecasting Domestic Tourism Demand: Application to Las Vegas Arrivals Data," Journal of Travel Research, 31(1):36-41.

Witt, C. A., S. F. Witt, and N. Wilson 1994 "Forecasting International Tourist Flows," Annals of Tourism Research, $\mathbf{2 1}(3): 612-28$. 